\title{
Controlling sintering and grain growth of nanoceramics
}

\section{(Controlando a sinterização e o crescimento de grão de nanocerâmicas)}

\author{
R.H.R. Castro ${ }^{1 *}$ \\ ${ }^{1}$ University of California, Davis, Department of Materials Science and Engineering, California, USA
}

\begin{abstract}
Sintering and grain growth are fundamental processes affecting microstructural evolution of ceramics. The phenomenological models describing these processes as found in textbooks are simplifications of the very dynamic set of system's parameters, which lead to limited predictability and the need for extensive empirical analyses for process optimization. One such simplification is the underestimation of interfacial energies and their relationships with diffusion paths and growth control. The goal of this paper is to clarify how thermodynamics of interfaces can provide opportunities for a more refined control of ceramic processing. On the first part of this paper we discuss the relevance of grain boundary energies in grain growth, showing that although grain boundary mobility is the preferred parameter choice for designing of grain growth inhibition, recent studies demonstrate dopants can be selected to annihilate the process driving force and enable thermally (meta)stable nanoceramics. In the second part of the paper, we point out shortcomings from the current sintering theory and discuss that both surface and grain boundary energies with their associated rates of interfacial area evolution represent a more comprehensive sintering description. This perspective offers tunable parameters that may set a new foundation for the design of sintering aids for optimal densification.
\end{abstract}

Keywords: sintering, grain growth, thermodynamics, interfaces.

\section{Resumo}

Sinterização e crescimento de grão são processos fundamentais que afetam a evolução microestrutural das cerâmicas. Os modelos fenomenológicos que descrevem esses processos, conforme encontrados nos livros didáticos, são simplificações do conjunto altamente dinâmico de parâmetros do sistema, o que leva à previsibilidade limitada e à necessidade de extensas análises empíricas para otimização de processos. Uma tal simplificação é a subestimação de energias interfaciais e suas relações com caminhos de difusão e controle de crescimento. O objetivo deste artigo é esclarecer como a termodinâmica das interfaces pode fornecer oportunidades para um controle mais refinado do processamento de cerâmica. Na primeira parte deste artigo discutese a relevância das energias de contorno de grão no crescimento de grão, mostrando que embora a mobilidade de contorno de grão seja a escolha preferida para projetar a inibição do crescimento de grão, estudos recentes demonstram que os dopantes podem ser selecionados para aniquilar a força motriz do processo e possibilitar nanocerâmicas (meta)estáveis termicamente. Na segunda parte do artigo, apresentam-se as deficiências da atual teoria da sinterização e discute-se que ambas energias de contorno de grão e de superfície, com suas taxas associadas de evolução da área interfacial, representam uma melhor descrição da sinterização. Essa perspectiva oferece parâmetros ajustáveis que podem estabelecer uma nova base para o design de aditivos de sinterização para uma densificação ótima.

Palavras-chave: sinterização, crescimento de grão, termodinâmica, interfaces.

\section{INTRODUCTION}

Sintering and grain growth have been the topic of extensive research in the past several decades owing to the fact they constitute the basic processes to control and optimize target microstructures in ceramics. Fundamental descriptions of these processes date from late 1940's [1-4] and although those concepts were developed for metals, they were adopted to describe crystalline ceramics with only few adjustments. One of the most critical assumptions of the earlier models is the underestimation of the role of interfacial energies in governing the process. For instance, when describing grain growth, the classical quadratic equation is commonly used [1]:

* (D) https://orcid.org/0000-0002-7574-7665

$$
\mathrm{d}^{2}-\mathrm{d}_{0}^{2}=2 \mathrm{M}_{\mathrm{gb}} \cdot \gamma_{\mathrm{gb}} \cdot\left(\mathrm{t}-\mathrm{t}_{0}\right)
$$

where, $d_{0}$ is the grain size at the initial time $t_{0}, M_{g b}$ is the mobility of the grain boundary and $\gamma_{\mathrm{gb}}$ is the grain boundary energy. The parabolic trend has been extensively observed in the literature, although some works arbitrarily replace the exponent 2 by ' $n$ ' to allow proper fitting of the sample's coarsening behavior [5]. This procedure has an insufficient physical basis and fitting can be generally achieved by utilizing quantifiable dragging forces instead [6]. Because the grain boundary mobility has an exponential dependence, grain boundary energy is deemed not as relevant when describing grain growth. Therefore, when describing the role of impurities (or dopants/additives) on the grain boundary velocity, the effect of the local chemistry on the grain boundary energy is overlooked. Recently, data on 
grain boundary energies have shown that impurities may significantly lower the grain boundary energy of ceramics down to values below $0.025 \mathrm{~J} / \mathrm{m}^{2}$ [7]. While this may seem irrelevant front the exponential dependence of the grain boundary mobility, some impurities may have only minor effects on the activation energy and mobility, and thus the system will be mostly controlled by the thermodynamic aspect, as observed in Gd-doped yttria-stabilized zirconia discussed in the next session.

The description of sintering found in the literature also significantly simplifies the dependence of sintering paths on interfacial energies [8]. When describing the initial stage of (solid-state) sintering, the conventional approach assumes grain boundary energy as much smaller than the surface energy and thus the energetic dependence of the process is founded on the later alone. Although this assumption is sometimes not directly stated, if one assumes that the main driving force for the process is the difference in surface curvature between the particle and the neck between touching particles, only the surface energy (divided by the radius) is accounted as the local driving force and grain boundary energy is ignored. While this can be true for very large particles of materials with relatively low grain boundary energies being sintered, such as gold particles [9, $10]$, ignoring the effect of the grain boundary energy on the chemical potential difference of an atom moving from the surface of a crystalline ceramic particle to the neck is not easily defendable. However, historically this has not been questioned enough, mostly due to the lack of accurate data to test and evaluate these conventional models. Hence, because the surface curvature always brings a favorable sintering thermodynamics, the explanation regarding densification and non-densification behaviors during sintering become purely around mechanisms of mass transport [11]. In sintering textbooks, one may find tables describing materials sources and sink (which is always the neck) and the possible mass transport pathways: surface diffusion, lattice diffusion, grain boundary diffusion, etc., which are then related to the densification or non-densification behavior of the system $[8$, 12]. Within this framework, one describes the behavior of ceramics during sintering and interprets activation energies in terms of specific diffusion mechanisms. For instance, sintering of cubic $\mathrm{ZrO}_{2}$ would be mostly controlled by the grain boundary diffusion [13], while sintering of $\mathrm{SnO}_{2}$ is controlled by evaporation-condensation $[14,15]$.

The mechanistic description of sintering offers limited controlling parameters, with most related to time and temperature of sintering. For instance, different thermal cycles can promote densification without grain growth (avoiding non-densification mechanisms) by rapidly heating the sample to high temperatures to activate densification pathways while minimizing time exposure at a temperature in which only non-densification mechanisms, such as surface diffusion, are present $[8,16,17]$.

The role of dopants and sintering aids are then interpreted based on their expected effects on local diffusivities [18, 19]; for exemple, by lowering grain boundary diffusion due to dopant segregation one could benefit other mechanisms such as surface diffusion; alternatively, by increasing grain boundary diffusion by introducing impurity induced defects, one could potentially cause more densification in a system. While explanations based on this aspect of dopants vastly populate the literature on sintering, it constitutes an additional simplification of the problem related to the effect of ionic dopants (i.e. dopants in the form of ions) on the thermodynamics of the system, i.e. local chemical potentials.

As in any diffusion-controlled process, the diffusion direction must be controlled by gradients of chemical potential. The conventional sintering framework assumes this is constant even when dopants are introduced. However, in particular when dopants are segregated to interfaces, both the grain boundaries and surfaces are affected [2022]. One may then say that this would be essentially responsible for changes in mass transport mechanisms. In a coming session, we will describe the role of dopants in controlling densification and non-densification mechanisms in an attempt to demonstrate that both thermodynamics and kinetics are necessary conditions for densification. The aim is not to invalidate the conventional mass transport mechanistic analysis, but to support it by solidifying that interfacial thermodynamics is directly connected to the mechanisms by the thermodynamic extremal principle [23], which states that a system will evolve its microstructure in the direction of highest rate of energy decrease - hence local atomic mobility and thermodynamics of interfaces are interconnected.

\section{THERMODYNAMICS OF GRAIN GROWTH}

Refined control over processing can allow manufacturing of samples with very small grain sizes $(<10 \mathrm{~nm})$ which demonstrate unprecedented properties, such as for example $\mathrm{MgAl}_{2} \mathrm{O}_{4}$ dense ceramics with $7 \mathrm{~nm}$ grain sizes possessing hardness that surpasses sapphire [24]. However, grain growth is a thermally activated process and coarsening is deemed inevitable if nanocrystalline ceramics are exposed to high temperature. In order to diminish grain boundary velocity, and hence inhibit grain growth, both mobility and grain boundary energy can be seen as potential controlling variables as shown in Eq. A. However, until recently, the grain boundary energy has not been considered a variable to design (meta)stable nanocrystalline ceramics. Following theoretical framework developed for the control of nanocrystalline metal alloys [25-30], a few papers have reported virtual stopping of grain growth of ceramics by introducing dopants targeting a reduction of the grain boundary energy [7, 31-33]. The grain boundary energy was lowered to essentially zero [7], signifying a negligible driving force for coarsening.

The effect of dopant segregation on the grain boundary energy can be described by an equation derived from the Gibbs absorption equation for dilute solutions [29]:

$$
\gamma_{\mathrm{gb}}=\gamma_{0}-\Gamma_{\mathrm{B}}\left(\mathrm{RT} \ln X_{\mathrm{B}}^{\text {bulk }}-\Delta \mathrm{H}_{\mathrm{seg}}\right)
$$


Here, $\gamma_{\mathrm{gb}}$ is the grain boundary energy with solute segregation, $\gamma_{0}$ is the grain boundary energy of the host material (solvent), $\Gamma_{B}$ is the solute excess, $\Delta H_{\text {seg }}$ the enthalpy of segregation, and $X_{B}^{\text {bulk }}$ the bulk solute content. Fig. 1 shows a schematic representation of the behavior of the grain boundary energy as a function of dopant concentration, $\mu_{\mathrm{B}}$, with a favorable enthalpy of segregation. For low concentrations, it is not uncommon to observe the formation of solid solution within the bulk prevailing against the segregation behavior. This happens because the total energy of the system (host+dopant) is still lower when comparing with a scenario with segregation without solubility. The extension of this zone is dependent on the enthalpy of mixing, the enthalpy of segregation and the availability of the grain boundaries since the total energy of the system accounts for the bulk volume and the total interfacial areas. There is an eventual crossover of energies that leads to segregation and a systematic decrease in the grain boundary energy as observed in the figure. The slope of this decay is dependent on the excess quantity, and is not necessarily linear because parameters in Eq. A are not constants. The segregation zone also comes to an end which is dependent to the saturation of the interface and the free energy for the formation of a second phase of the dopant derived oxide or a mixed oxide (dopant+host cations) [29]. For higher dopant concentrations, precipitation is observed in either a crystalline or amorphous second phase. From a kinetic perspective of grain growth, this stage will alter coarsening by Zener pinning, i.e. grain boundary mobility is

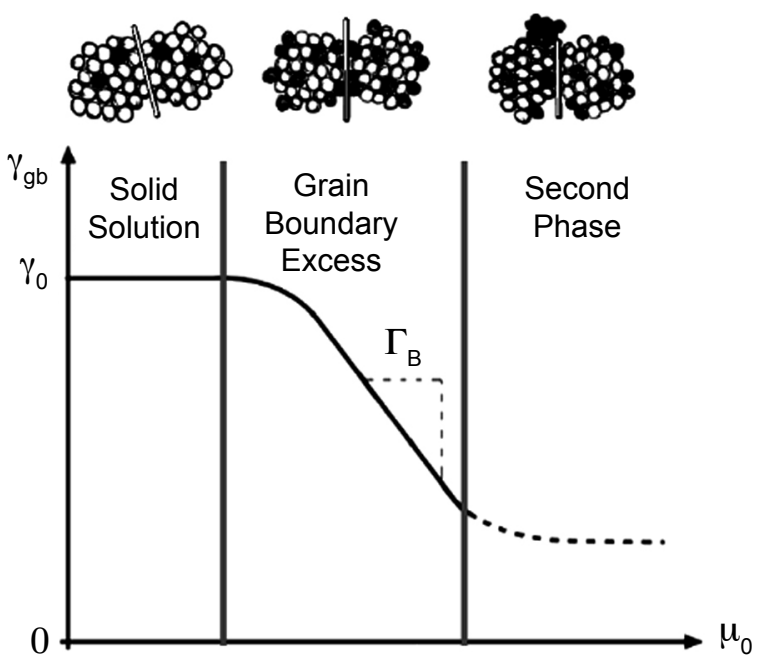

Figure 1: Schematic representation of the role of a dopant B (impurity) on the grain boundary energies of ceramics. Solid solution leads to negligible changes, followed by the grain boundary excess (segregation) that shows pronounced decrease and subsequent second phase nucleation when energy changes level off.

[Figura 1: Representação esquemática do papel de um dopante $B$ (impureza) nas energias de contorno de grão da cerâmica. Solução sólida leva a mudanças insignificantes, seguida pelo excesso de contorno de grão (segregação) que mostra diminuição pronunciada e subsequente nucleação da segunda-fase quando a energia muda de nível.] lowered due to drag forces [8]. This concept is well described in the literature, but fundamentally different than when only grain boundary excess (segregation without precipitation) is observed. This case is of more interest though because the system is still a single phase, and relevant functional properties, such as optical transparency, can be maintained.

The control of grain growth by targeting grain boundary energy reduction can be well understood in the gadoliniumdoped yttria-stabilized zirconia (YSZ) system [7, 31]. Although this may sound like a complicated system, it works well as a model since YSZ itself behaves like a host, and Gd as a dopant with expected segregation. This dopant is selected based on the difference of ionic radius as compared to $\mathrm{Y}$, and because it has the same valence, so that the thermochemistry could be better understood and controlled [34]. In truth, there is yet no hard rule for selection of dopants prone to segregation for grain growth control since data on enthalpy of segregation is very scarce. It has been recently proposed that atomistic simulations can accurately predict the segregation behavior in oxides [20, 21], but more studies are required for full validation.

Fig. 2 shows a plot on the effect of Gd on the grain growth of nanocrystalline YSZ as reported by Nafsin et al. [31]. The effect of $4 \mathrm{~mol} \% \mathrm{Gd}$ is evident on promoting grain growth inhibition at any given temperature in the studied range. For the Gd-containing samples, the grain sizes level off after a certain time, which is not observed in YSZ that still presents a positive growing slope even after $1000 \mathrm{~min}$ of annealing. In truth, a complete stop of coarsening can only happen if the driving force is negligible since any drag force would still result in limited but still positive growth kinetics. To evaluate the driving force of coarsening, Nafsin and Castro [7] studied the grain boundary energy as a function of grain size and demonstrated that with $4 \mathrm{~mol} \% \mathrm{Gd}$, the grain boundary energy for a grain size of $13 \mathrm{~nm}$ is $0.5 \mathrm{~J} / \mathrm{m}^{2}$, which is already reduced as compared to YSZ alone [35]. Interestingly, as the grains grow, this energy is found to decrease to below $0.025 \mathrm{~J} / \mathrm{m}^{2}$ when grain sizes are around $50 \mathrm{~nm}$ [7], consistently with predictions from Eq. B. The reduction in the energy as a function of grain size is related to the local dopant enrichment (increased excess) caused by the reduction in the grain boundary area. That is, since the dopant has a favorable enthalpy of segregation, the reduction in area will cause a net increase in its concentration, acting similarly to an increase in the total concentration of the general composition [31].

While one may expect that the grain boundary energy shall have an effect on the grain growth following Eq. A, one can be skeptical as to the fact this is the major player in controlling grain growth. It is therefore relevant to determine the grain boundary mobility itself, including its activation energy, to enable a quantitative analysis of the extension of both kinetics and thermodynamic contributions. This can be done by plotting a graph of $\left(\mathrm{d}^{2}-\mathrm{d}_{0}{ }^{2}\right)$ versus $\left(\mathrm{t}-\mathrm{t}_{0}\right)$ and quantifying the slope, which is $2 \mathrm{M}_{\mathrm{gb}} \gamma_{\mathrm{gb}}$. By plugging in the experimental data for the grain boundary energies, the actual mobility for a given temperature can be extracted. Nafsin 


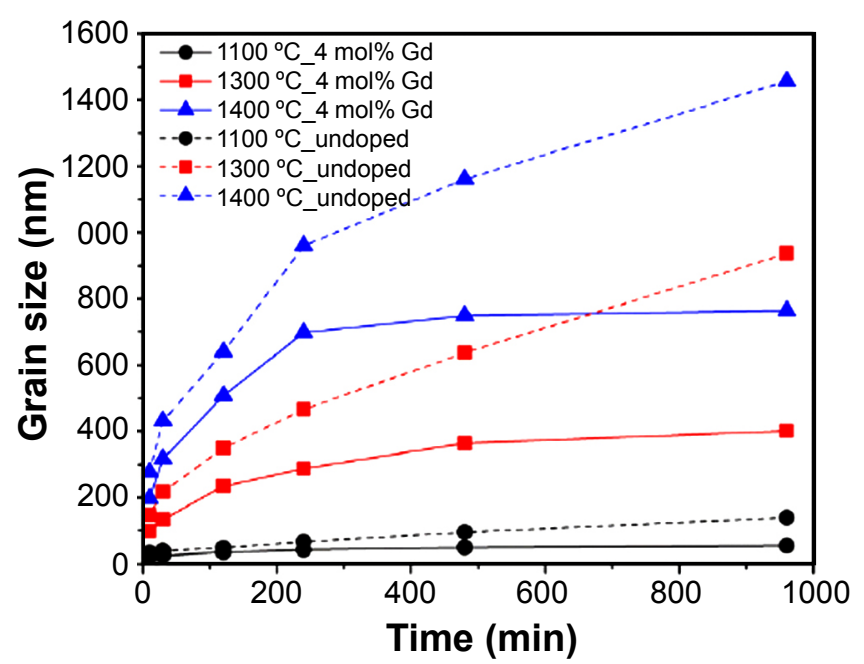

Figure 2: Grain size as a function of time of yttria-stabilized zirconia with and without gadolinium for different temperatures (as indicated in the legend). Grain growth of Gd-containing samples is inhibited, as reported by Nafsin et al. [31].

[Figura 2: Tamanho do grão em função do tempo de zircônia estabilizada com ítria com e sem gadolínio para diferentes temperaturas (conforme indicado na legenda). $O$ crescimento de grão de amostras contendo $G d$ é inibido, conforme relatado por Nafsin et al. [31].]

et al. [31] have carefully performed this experiment and demonstrated that gadolinium causes a negligible change in the grain boundary mobility of YSZ, and only slightly increases the activation energy from 3.7 to $3.79 \mathrm{eV}$ with the addition of $4 \mathrm{~mol} \% \mathrm{Gd}$. This increase suggests the major contributor for grain growth hindering is indeed the grain boundary energy, although a small contribution is related to mobility still. These results contrast with some seminal works on grain growth control of oxides that defend the hypothesis that ionic dopants primarily affect the grain boundary mobility [36, 37], breaking the paradigm related to the relevance of thermodynamics in grain growth control.

However, it is important to note that one should not expect all dopants to have negligible effects on mobility. For instance, dopants with valence states different than the host are expected to increase defect concentration and thus significantly affect the grain boundary mobility in addition to its thermodynamics. This has been observed in Mn-doped $\mathrm{CeO}_{2}$, for instance, which shows massive grain growth during sintering although the dopant is segregated and the grain boundary energy remarkably reduced [38,39].

\section{THERMODYNAMICS OF SINTERING}

Collectively addressing the sintering works by Coble [40, 41], Kingery [42], Kuczynski [4, 43] and other 'founding fathers' of our current sintering theories, it is surprising they do not satisfactorily account for the thermodynamics of the grain boundaries as a relevant parameter in modeling and interpreting sintering data. The most prominent works on the thermodynamics of solid-state sintering came from Lange et al. [44-46], that although using simplified geometries, could demonstrate the grain boundary energy, and its effects on the dihedral angles, had an important role in determining sintering-stress. There is no mention of a connection between this apparent thermodynamic dependence and the conventional mechanisms of sintering, but a rational analysis can tell these are apparently incompatible models as one has the dihedral angle as controlling the driving force while the other assumes the curvature potential as the sole driving force for the process.

One may find experimental evidence that the curvature potential cannot actually account for the driving force of sintering alone if grain boundary energies are not negligible. This was systematically demonstrated by Chang et al. [47] when studying the sintering of $\mathrm{SnO}_{2}$ and showed that pore volume is a function of dihedral angle. In their experiments, Mn was used as a dopant to create a specific condition in which the dihedral angle is a function of temperature because of the change in segregation behavior of $\mathrm{Mn}$. At high temperatures $\left(1300^{\circ} \mathrm{C}\right), \mathrm{Mn}$ is reduced to $2+$ and segregation to grain boundaries is observed. At lower temperatures $\left(800{ }^{\circ} \mathrm{C}\right), \mathrm{Mn}$ is oxidized to $4+$ and segregation is reduced because the charge and size mismatches are different. This resulted in a dihedral angle of $\sim 104.5^{\circ}$ at $1300^{\circ} \mathrm{C}$ and $\sim 97^{\circ}$ at $800{ }^{\circ} \mathrm{C}$. The interesting observation was that if the sample is placed at $1300{ }^{\circ} \mathrm{C}$, densification occurs with pronounced pore elimination, but if subsequently the already densified sample is placed at $800^{\circ} \mathrm{C}$, the pores re-opened and density decreases (with particles' separation and pellet inflation) in a de-sintering phenomenon. This is a demonstration that mass is flowing against the curvature potential since they are driven by the interfacial energies instead.

Despite the apparent doubts on the foundations of the theory, sintering mechanisms are the most common elements for sintering studies found in the literature and have led to some level of control and understanding of sintering in the past. The reason could be that the mechanisms of mass transport and their geometrical 'consequences' to the particulate system are not a result of local diffusivities as proposed before, but rather on the thermodynamics of the system affecting mass flow by changing local chemical potentials. Thermodynamic extremal principle applied to materials processing states that the path with higher energy 'dissipation rate' should prevail [48]. Energy dissipation is related to both thermodynamics and kinetics, which translating into common sintering terms means that both interfacial energies (for grain boundaries and surfaces) along with diffusion coefficients are defining the microstructural evolution.

An interesting consequence of this new sintering optics is that the path of higher energy dissipation may be a nondensification path, such as what is observed in $\mathrm{SnO}_{2}$ [13]. In this system, grain growth is observed, but pores are also growing at similar rates. This leads to an energy decrease by grain boundary and surface area shrinkage, but no pore volume elimination. While conventional theories state this is a result of an evaporation-condensation mechanism, this 
new perspective points out that because $\mathrm{SnO}_{2}$ has high grain boundary energy at elevated temperatures, a low dihedral angle is persistent during sintering, and pores cannot be eliminated [49]. This does not conflict with the mechanism, which may (or may not) be evaporation-condensation, but the point made here is that the mechanism itself would be a consequence, not the cause, of the specific microstructural evolution.

A more recent thermomechanical description of sintering has incorporated both kinetics and thermodynamics of sintering. The model is still incomplete, but it connects the grain size and the density evolutions during sintering by a term that represents the total energy variance from surface and grain boundary elimination/formation along the process. The model for isothermal sintering can be summarized in one phenomenological equation $[32,50]$ :

$$
\left(\frac{1}{\rho}-\frac{1}{\rho_{0}}\right)=\frac{6 \mathrm{~V}}{\mathrm{P}}\left(\gamma_{\mathrm{s}} \frac{\mathrm{dA}_{\mathrm{GG}}^{\mathrm{P}}}{\mathrm{dA}_{\mathrm{T}}}-\gamma_{\mathrm{gb}} \frac{\mathrm{dA}_{\mathrm{GB}}}{\mathrm{dA}_{\mathrm{T}}}\right)\left(\frac{1}{\mathrm{~d}}-\frac{1}{\mathrm{~d}_{0}}\right)
$$

or simply:

$$
\left(\frac{1}{\rho}-\frac{1}{\rho_{0}}\right)=\frac{6 \mathrm{~V}}{\mathrm{P}} \mathrm{K}\left(\frac{1}{\mathrm{~d}}-\frac{1}{\mathrm{~d}_{0}}\right)
$$

Here, $\rho$ is the measured density of the sample during sintering, $\rho_{0}$ is the initial density (density when the system is already at the sintering temperature), $\mathrm{V}$ is the molar volume, $\mathrm{P}$ is the pressure, $d$ is the grain size at a given density and $d_{0}$ the grain size at initial density. $\mathrm{K}$ is simply the second term in parenthesis in Eq. C. $\mathrm{dA}_{\mathrm{GG}}^{\mathrm{P}}$ is the variation of pore area coming from grain coarsening, $\mathrm{dA}_{\mathrm{GB}}$ is the grain boundary area evolution during sintering, and $\mathrm{dA}_{\mathrm{T}}$ is the total interfacial area evolution. This model implies that densification and grain growth are actually interconnected, as previously proposed by Lange [44] as well, and the connection between these two quantities is dependent on the interfacial energies and rate of change of interfacial areas. These last ones have certainly a connection to diffusion rates, but this has not been mathematically established yet.

One observes from Eq. $\mathrm{D}$ that the term $\mathrm{K}$ and its multiplier govern the density evolution in terms of its connection with the grain size. When $\mathrm{K}$ tends to zero, very limited densification with pronounced grain growth is observed, consistent with experiments on $\mathrm{SnO}_{2}$, for instance. High $\mathrm{K}$ values would lead to more densification with less grain growth, which is generally what is desirable in sintering. The model thus suggests that having favorable thermodynamics is a necessary but not sufficient condition for sintering as the interfacial area derivatives play equivalent roles in controlling the slope.

\section{Discussion of experimental observations on sintering} thermodynamics

To better understand the combined effects of thermodynamics and kinetics on sintering one may analyze recent results on the sintering of cubic zirconia (yttriastabilized) and the effect of dopants [51, 52]. Unlike several past studies on sintering, due to advances in experimental thermodynamics, recent works have finally been able to provide thermodynamic data for the existing interfaces, quantifying the effect of dopants for a complete sintering analysis. Fig. 3 shows a plot of grain sizes versus density for YSZ and YSZ doped with $\mathrm{La}$ or $\mathrm{Mn}$ at $2 \mathrm{~mol} \%$ as well as density as a function of time for pellets sintered at $1300{ }^{\circ} \mathrm{C}$ using fast firing. It is evident that La is inhibiting densification while Mn works as a sintering aid. In truth, YSZ itself already
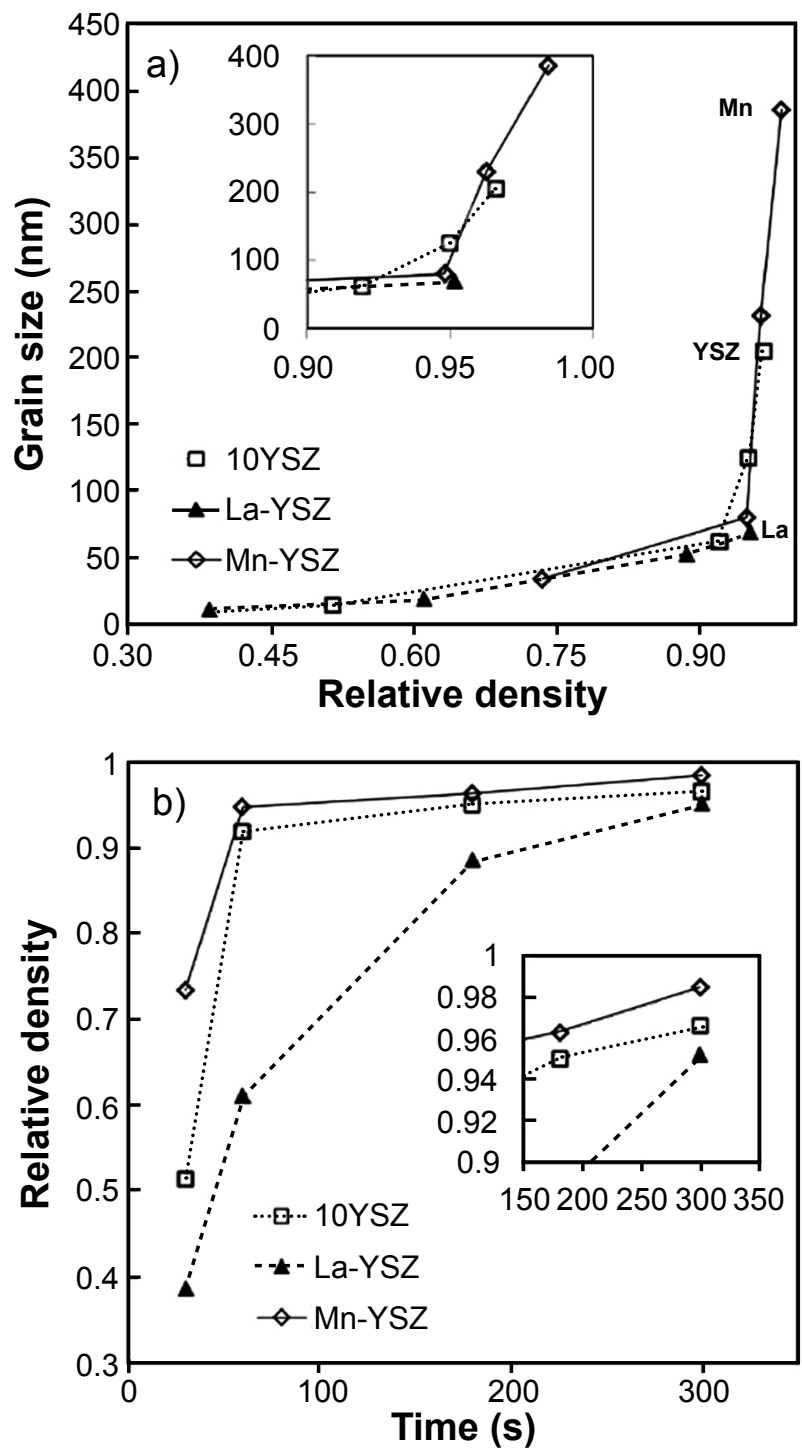

Figure 3: (a) Grain size as a function of relative density for YSZ, La-doped YSZ and Mn-doped YSZ sintered at $1300{ }^{\circ} \mathrm{C}$ for different times. (b) Density as a function of time for the samples shown in (a) for reference. Inserts are the same plot by zoomed-in to clarify differences. Replots from [51, 52].

[Figura 3: (a) Tamanho de grão em função da densidade relativa para YSZ, YSZ dopado com La e YSZ dopado com Mn sinterizados a $1300{ }^{\circ} \mathrm{C}$ por diferentes tempos. (b) Densidade em função do tempo para as amostras mostradas em (a) para referência. Inserções são o mesmo gráfico ampliado para mostrar as diferenças. Replotados de $[51,52]$. 


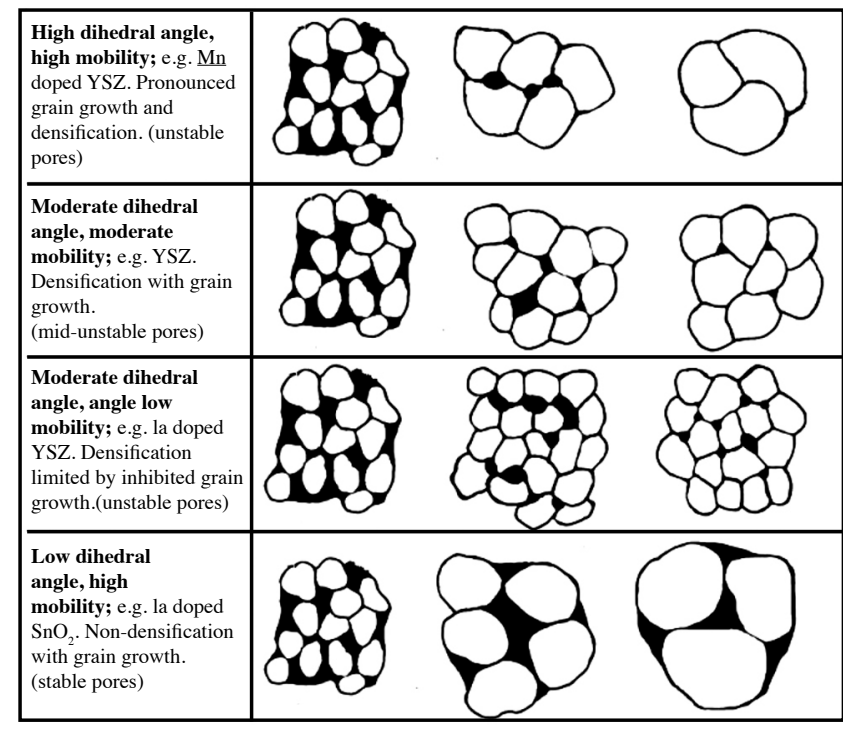

Figure 4: Schematic representation of microstructural evolutions (pore/grain size) at different stages of sintering as a function of thermodynamic and kinetic conditions. Note that even when pores are unstable (as shown in Mn and La-doped YSZ by the pore geometry), the lack of mobility will limit densification.

[Figura 4: Representação esquemática das evoluções microestruturais (poro/tamanho de grão) em diferentes estágios de sinterização em função das condições termodinâmica e cinética. Note que, mesmo quando os poros são instáveis (como mostrado em YSZ dopado com Mn e La pela geometria do poro), a falta de mobilidade limita a densificação.]

shows densification (which is attributed in the literature to an active grain boundary diffusion mechanism of densification [11]), but $\mathrm{Mn}$ increased the final density and accelerated densification though simultaneously causing rapid grain growth. La, on the other hand, limited the final density while also inhibiting grain growth. Fig. 4 schematically represents the observed microstructural evolution for the three systems.

An important observation here is that both dopants are reported to segregate to the interfaces and to modify both grain boundary and surface energies [51-53]. As seen in Fig. 4 and Table I, the dihedral angle calculated from the measured interfacial energies for YSZ is already suggesting significant sintering stress in the context of Lange's description of sintering thermodynamics [45]. For comparison, $\mathrm{SnO}_{2}$, a nondensification system shows a dihedral angle of $100^{\circ}$ [49] and MgO-doped $\mathrm{Al}_{2} \mathrm{O}_{3}$ averages $114.5^{\circ}$ [32]. Both $\mathrm{Mn}$ and $\mathrm{La}$ though clearly increased the dihedral angle by roughly $10 \%$, which is a result of both surface and grain boundary energy changes. However, Li et al. [51, 52] report that although both $\mathrm{Mn}$ and La do segregate to the interfaces (and thus the observed energy changes), La causes inhibition of grain growth while Mn enhances it. Segregation of ions is typically rationalized as pinning for grain boundary movement from either a thermodynamic or a kinetic perspective [54]. But Mn plays a different role as it affects the local chemistry of the grain boundaries in a way it results in a reduction of activation energy of grain boundary migration in YSZ [52], in a similar behavior as observed in $\mathrm{Mn}$-doped $\mathrm{CeO}_{2}$ [39]. La, on the other hand, slows down the grain boundary movement to the point the system will be trapped in a metastable condition and will not achieve full densification.

Lange and Kellett [46] have pointed out that these metastable conditions are often reached during sintering, but the existence of grain boundary mobility would move the system away from the metastable energy valleys and allow continuous densification. In Mn-doped YSZ, the mobility is so high and the dihedral angle so favorable that densification naturally occurs. Although La-doped YSZ has the 'right' thermodynamics, it gets kinetically trapped at metastable states and densification is hindered.

Aperfect example to demonstrate the other side of the model is $\mathrm{SnO}_{2}$, in which the thermodynamics is unfavorable although coarsening is fairly active [12]. As noted before, the dihedral angle for $\mathrm{SnO}_{2}$ is about $100^{\circ}$. However, diffusion at the grain boundaries can be easily activated and hence, the sintering behavior of $\mathrm{SnO}_{2}$ is characterized by grain enlargement without any significant densification (as schematically shown in Fig. 4). This is because energy dissipation occurs mostly by surface elimination since because the grain boundary energy of $\mathrm{SnO}_{2}$ is too high, it is energetically expensive to increase grain boundary area (required for densification) in the system.

\section{FINAL REMARKS}

It is hardly the objective of this paper to end the discussion of how to control solid-state sintering. Instead, the aim was to bring a new breath to an old model that has obvious limitations that have been pointed out several times in the literature. By bringing the thermodynamic concepts into the universe of mass transport mechanisms one may find a more convincing way to describe densification and non-densification mechanisms

Table I - Grain boundary and surface energies of YSZ and doped YSZ, as well as the calculated dihedral angle. Data extracted from $[48,49] . \bar{\gamma}_{\mathrm{s}}$ is average surface energy, $\bar{\gamma}_{\mathrm{gb}}$ is the average grain boundary energy and $\varphi$ is the calculated dihedral angle. [Tabela I - Energias de superfície e de contorno de grão de YSZ e YSZ dopado, bem como o ângulo diedro calculado. Dados extraídos de $[48,49] . \bar{\gamma}_{s}$ é a energia superficial média, $\overline{\gamma_{\mathrm{gb}}}$ é a energia média de contorno de grão e $\varphi$ é o ângulo diedro calculado.]

\begin{tabular}{ccccc}
\hline Sample & $\bar{\gamma}_{\mathrm{s}}\left(\mathrm{J} / \mathrm{m}^{2}\right)$ & $\bar{\gamma}_{\mathrm{gb}}\left(\mathrm{J} / \mathrm{m}^{2}\right)$ & $\bar{\gamma}_{\mathrm{gb}} / \bar{\gamma}_{\mathrm{s}}$ & $\varphi\left(^{\circ}\right)$ \\
\hline 10YSZ & $0.95 \pm 0.01$ & $0.69 \pm 0.02$ & $0.73 \pm 0.03$ & $137.19 \pm 0.03$ \\
2La-YSZ & $0.80 \pm 0.05$ & $0.41 \pm 0.06$ & $0.52 \pm 0.16$ & $150.04 \pm 0.11$ \\
2Mn-YSZ & $0.71 \pm 0.01$ & $0.38 \pm 0.01$ & $0.54 \pm 0.01$ & $148.6 \pm 0.4$ \\
\hline
\end{tabular}


rather than the conventional geometrical-based assumptions. We presented some well-controlled experimental results pointing out that a favorable thermodynamics (i.e. large dihedral angles) is needed for densification and is directing mass towards the formation of grain boundaries and thus densification. On the other hand, if the grain boundary energy is too small, grain growth is inhibited to the point that densification cannot happen because the system gets trapped in metastable energetic states. It is apparent that densification with minimal grain growth thus shall rely on a dopant that increases dihedral angle with moderate grain growth mobility still existing. The existing of such 'minimal coarsening' has then to be accepted as necessary and inevitable in the design of conventional pressureless sintering. In the context of Eq. C though, it is obvious that an increased pressure will result in massive densification with minimal grain growth independent on the system diffusivity or thermodynamics.

\section{ACKNOWLEDGEMENT}

The author gratefully acknowledge the National Science Foundation DMR Ceramics 1609781 for support of this work.

\section{REFERENCES}

[1] J.E. Burke, AIME Met. Tech. TP 2472 (1948) 1.

[2] D.G. Cole, P. Feltham, E. Gillam, Proc. Phys. Soc., B 67 (1954) 131.

[3] W.D. Kingery, J.M. Woulbroun, F.R. Charvat, J. Am. Ceram. Soc. 46 (1963) 391.

[4] G.C. Kuczynski, Adv. Colloid Interface Sci. 3 (1972) 275.

[5] H. Hu, B.B. Rath, Metall. Trans. 1 (1970) 3181.

[6] M.M. Gong, F. Liu, in: Sintering, Eng. mater., Ed. R.H.R. Castro, K. Van Benthem, Springer-Verlag, Berlin (2013) 35. [7] N. Nafsin, R.H.R. Castro, J. Mater. Res. 32 (2017) 166.

[8] S.-J.L. Kang, Sintering: densification, grain growth \& microstructure, Elsevier, New York (2005).

[9] J.E. Milliard, M. Cohen, B.L. Averbach, Acta Metall. 8 (1960) 26.

[10] L. Yang, Y. Gan, Y. Zhang, J.K. Chen, Appl. Phys. A 106 (2012) 725.

[11] R.H.R. Castro, in: Mechanisms of convention nanodensification and field assisted processes, Ed. R.H.R. Castro, K. Van Benthem, Springer-Verlag, Berlin Heidelberg (2013) 1.

[12] M.N. Rahaman, Ceramic processing and sintering, CRC Press (2003).

[13] X. Song, J. Lu, T. Zhang, J. Ma, J. Am. Ceram. Soc. 94 (2011) 1053.

[14] C.-H. Chang, R.H.R. Castro, J. Mater. Res. 29 (2014) 1034.

[15] E.R. Leite, J.A. Cerri, E. Longo, J.A. Varela, C.A. Paskocimas, J. Eur. Ceram. Soc. 21 (2001) 669.

[16] D. Hotza, D.E. García, R.H.R. Castro, Int. Mater. Rev. 60 (2015) 353.
[17] D.E. García, J. Seidel, R. Janssen, N. Claussen, J. Eur. Ceram. Soc. 15 (1995) 935.

[18] J.A. Varela, L.A. Perazolli, E. Longo, E.R. Leite, J.A. Cerri, Radiat. Eff. Defects Solids 146 (1998) 131.

[19] T. Kim, D. Kim, S. Kang, J. Alloys Compd. 587 (2014) 594.

[20] M.M. Hasan, P.P. Dholabhai, R.H.R. Castro, B.P. Uberuaga, Surf. Sci. 649 (2016) 138.

[21] M.M. Hasan, S. Dey, N. Nafsin, J. Mardinly, P.P. Dholabhai, B.P. Uberuaga, R.H.R. Castro, Chem. Mater. 28 (2016) 5163.

[22] M.M. Hasan, P.P. Dholabhai, S. Dey, B.P. Uberuaga, R.H.R. Castro, J. Eur. Ceram. Soc. 37 (2017) 4043.

[23] F.D. Fischer, J. Svoboda, H. Petryk, Acta Mater. 67 (2014) 1.

[24] N.F. Muche, J. Drazin, J. Mardinly, S. Dey, R.H.R. Castro, Mater. Lett. 186 (2017) 298.

[25] R. Kirchheim, Acta Mater. 55 (2007) 5139.

[26] R. Kirchheim, Acta Mater. 55 (2007) 5129.

[27] F. Liu, R. Kirchheim, J. Cryst. Growth 264 (2004) 385.

[28] F. Liu, R. Kirchheim, Scripta Mater. 51 (2004) 521.

[29] R. Kirchheim, Acta Mater. 50 (2002) 413.

[30] T. Chookajorn, H.A. Murdoch, C.A. Schuh, Science 337 (2012) 951.

[31] N. Nafsin, J.A. Aguiar, T. Aoki, A.M. Thron, K. van Benthem, R.H.R. Castro, Acta Mater. 136 (2017) 224.

[32] R.H.R. Castro, D. Gouvêa, J. Am. Ceram. Soc. 99 (2016) 1105.

[33] M.M. Gong, R.H.R. Castro, F. Liu, J. Mater. Sci. 50 (2015) 4610.

[34] P. Wynblatt, G.S. Rohrer, F. Papillon, J. Eur. Ceram. Soc. 23 (2003) 2841.

[35] D.V. Quach, R.H. Castro, J. Appl. Phys. 112 (2012) 083527.

[36] P.L. Chen, I.W. Chen, J. Am. Ceram. Soc. 79 (1996) 1801.

[37] P.L. Chen, I.W. Chen, J. Am. Ceram. Soc. 79 (1996) 1793.

[38] L. Wu, J.A. Aguiar, P.P. Dholabhai, T. Holesinger, T. Aoki, B.P. Uberuaga, R.H.R. Castro, J. Phys. Chem. C 119 (2015) 27855.

[39] L. Wu, P.P. Dholabhai, B.P. Uberuaga, R.H.R. Castro, Cryst. Growth Des. 17 (2017) 446.

[40] R.L. Coble, J. Appl. Phys. 32 (1961) 787.

[41] R.L. Coble, J. Appl. Phys. 32 (1961) 793.

[42] W.D. Kingery, M. Berg, J. Appl. Phys. 26 (1955) 1205.

[43] G.C. Kuczynski, J. Appl. Phys. 20 (1949) 1160.

[44] F.F. Lange, J. Eur. Ceram. Soc. 28 (2008) 1509.

[45] B.J. Kellett, F.F. Lange, J. Am. Ceram. Soc. 72 (1989) 725.

[46] F.F. Lange, B.J. Kellett, J. Am. Ceram. Soc. 72 (1989) 735.

[47] C.-H. Chang, J.F. Rufner, K. van Benthem, R.H.R. Castro, Chem. Mater. 25 (2013) 4262.

[48] F.D. Fischer, J. Svoboda, H. Petryk, Acta Mater. 67 (2014) 1.

[49] C.H. Chang, R.H.R. Castro, J. Mater. Res. 29 (2014) 
1034.

[50] D. Gouvea, R.H.R. Castro, Appl. Surf. Sci. 217 (2003) 194.

[51] H. Li, S. Dey, R.H.R. Castro, Acta Mater. 150 (2018) 394.

[52] H. Li, F.L. Souza, R.H.R. Castro, J. Eur. Ceram. Soc.
38 (2018) 1750.

[53] M.M. Gong, S. Dey, L.J. Wu, C.H. Chang, H. Li, R.H.R. Castro, F. Liu, J. Mater. Sci. Technol. 33 (2017) 251.

[54] S. Dey, C.-H. Chang, M. Gong, F. Liu, R.H. Castro, J. Mater. Res. 30 (2015) 2991.

(Rec. 10/08/2018, Rev. 05/10/2018, Ac. 17/10/2018) 